\title{
Treatment with the herbal formula Songyou Yin inhibits epithelial-mesenchymal transition in hepatocellular carcinoma through downregulation of TGF- $\beta 1$ expression and inhibition of the SMAD2/3 signaling pathway
}

\author{
SUSU ZHENG ${ }^{*}$, QINGAN JIA* , HUJIA SHEN*, XIN XU, JIAJIA LING, CHUYU JING and BOHENG ZHANG
}

Liver Cancer Institute, Zhongshan Hospital, Fudan University, Shanghai 200032, P.R. China

Received January 22, 2016; Accepted December 9, 2016

DOI: $10.3892 / \mathrm{ol} .2017 .5700$

\begin{abstract}
It was previously reported that treatment with the herbal formula Songyou Yin (SYY) may serve a role in attenuating epithelial-mesenchymal transition (EMT). In the present study, the effect of treatment with SYY on transforming growth factor- $\beta 1$ (TGF- $\beta 1$ )-induced EMT was investigated and the potential underlying molecular mechanisms were evaluated. MHCC97H cells were pretreated with SYY for 4 weeks and subsequently named MHCC97HSYY cells. Simultaneously, MHCC97H cells were cultured for 4 weeks without SYY and used as a negative control. Western blot analysis and enzyme-linked immunosorbent assays demonstrated that treatment with SYY inhibited EMT-associated changes and TGF- $\beta 1$ expression in MHCC97H cells. MHCC97H and MHCC97HSYY cells were treated with $10 \mathrm{ng} / \mathrm{ml} \mathrm{TGF}-\beta 1$ to induce EMT. The results of the present study demonstrated that pretreatment with SYY markedly inhibited TGF- $\beta 1$-induced morphological changes, and reversed the expression of the EMT markers E-cadherin and N-cadherin. In addition, expression levels of the TGF- $\beta 1$ downstream proteins, phosphorylated mothers against decapentaplegic homologs (p-SMAD)2 and 3 , were reduced. Transwell assays indicated that pretreatment with SYY inhibited TGF- $\beta 1$-induced cancer cell invasion and migration. The results of the present study indicate that SYY inhibited EMT through attenuation of TGF- $\beta 1$ expression, and downregulation of p-SMAD2 and 3.
\end{abstract}

Correspondence to: Professor Boheng Zhang, Liver Cancer Institute, Zhongshan Hospital, Fudan University, 136 Yi Xue Yuan Road, Shanghai 200032, P.R. China

E-mail: zhang.boheng@zs-hospital.sh.cn

*Contributed equally

Abbreviations: TGF- $\beta 1$, transforming growth factor $\beta-1$; HCC, hepatocellular carcinoma; EMT, epithelial-mesenchymal transition

Key words: hepatocellular carcinoma, transforming growth factor- $\beta 1$, Songyou Yin, epithelial-mesenchymal transition

\section{Introduction}

Hepatocellular carcinoma (HCC) is the sixth most frequent cancer worldwide and the third leading cause of cancer-associated mortality (1). The survival rates of patients with HCC are unsatisfactory (2). Continuing problems in the management of HCC are tumor invasion and metastasis (3). Understanding the underlying molecular mechanisms of HCC invasion and metastasis may provide novel therapeutic targets. Increasing evidence indicates that epithelial-mesenchymal transition (EMT) serves an essential role in tumor invasion and metastasis $(4,5)$.

EMT is a cellular process during which polarized epithelial cells become motile and exhibit mesenchymal characteristics. The features of EMT include the loss of cell-cell adhesion, reorganization of the actin cytoskeleton and acquisition of increased migratory characteristics $(6,7)$. EMT is characterized by the upregulation of the mesenchymal marker N-cadherin, downregulation of the epithelial marker E-cadherin, and acquisition of fibroblast-like migratory and invasive phenotypes (8). Previous studies indicated that EMT serves a critical role in HCC invasion and metastasis (9-11).

Transforming growth factor- $\beta 1$ (TGF- $\beta 1$ ) is a multifunctional cytokine that regulates a range of cellular functions, including proliferation, differentiation, migration and apoptosis (12). In addition, TGF- $\beta 1$ is the primary mediator of EMT and is involved in epithelial-mesenchymal interactions during HCC metastasis $(13,14)$. The mothers against decapentaplegic homolog (SMAD) family of proteins has been demonstrated to be activated in response to members of the TGF- $\beta$ superfamily (15). During TGF- $\beta 1$-mediated EMT, TGF- $\beta 1$ binds to the TGF- $\beta$ type II receptor, and this binding induces the recruitment and phosphorylation of the type I TGF- $\beta$ receptor. The activated type I TGF- $\beta$ receptor subsequently induces the recruitment and phosphorylation of the receptor-regulated SMADs, SMAD2 and 3, which form heteromeric complexes with the common mediator SMAD, SMAD4 (16). The SMAD complexes translocate to the nucleus and mediate gene transcription by binding to SMAD binding elements contained within the promoter regions of target genes (17).

Traditional Chinese medicine has gained increasing attention in cancer therapy (18-20). Songyou Yin (SYY), 
a Chinese herbal formula consisting of four herbs: Salvia miltiorrhiza, Astragalus membranaceus, Lycium barbarum, Crataegus pinnatifida, and the Trionyx sinensis Wiegmann species of turtle, has been demonstrated to inhibit the development of HCC by inducing tumor cell apoptosis and reducing invasion (21). SYY attenuates hepatoma cell invasion and metastasis through the downregulation of cytokine secretion by activated hepatic stellate cells (22). Treatment with SYY has been demonstrated to inhibit the invasive and metastatic potential of HCC cells, and improve survival in nude mice models with chronic fibrosis, through the inhibition of cytokine secretion by activated hepatic stellate cells (23). Another report indicated that SYY serves a role in attenuating EMT by inhibiting EMT-associated molecular changes in oxaliplatin-treated tumor tissues and cell lines (24). However, the underlying molecular mechanisms of SYY-mediated EMT regulation have not been completely elucidated.

In the present study, the ability of SYY to inhibit HCC cell EMT was investigated, in addition to the molecular mechanism underlying the SYY-mediated decrease in TGF- $\beta 1$ expression.

\section{Materials and methods}

SYY preparation. The Chinese herbal formula SYY, a dietary component authorized by the China Food and Drug Administration (Beijing, China; Chinese health food approval no. G20070160), includes five Chinese medicinal extracts whose proportions, 'fingerprints' and protocols of preparation have previously been reported (21). The SYY used in the present study was obtained from Shanghai Fang Xin Pharmaceutical Technology Co., Ltd. (Shanghai, China; batch no. 20110401). An $800 \mathrm{mg} / \mathrm{ml} \mathrm{SYY} \mathrm{stock} \mathrm{solution} \mathrm{was}$ sterilized twice by $0.22-\mu \mathrm{m}$ Millex-GP Filter Unit (Millipore Express PES Membrane; EMD Millipore, Billerica, MA, USA) for further use.

Cell culture and reagents. The human hepatocellular carcinoma cell line MHCC97H (established at Fudan University, Shanghai, China) was used in the present study due to its metastatic potential. The cell line was established from a subcutaneous xenograft of a metastatic model of human HCC in nude mice (25). Similarly to a previous study (22), MHCC 97H cells pretreated with $2 \mathrm{mg} / \mathrm{ml} \mathrm{SYY} \mathrm{for} 4$ weeks were labeled as MHCC97HSYY cells. Cells were grown in $75 \mathrm{~cm}^{2}$ flasks and incubated at $37^{\circ} \mathrm{C}$ in an atmosphere containing $5 \% \mathrm{CO}_{2}$ All cells were cultured in Dulbecco's Modified Eagle Medium (DMEM; Thermo Fisher Scientific, Inc., Waltham, MA, USA) containing $10 \%$ fetal bovine serum (FBS; Thermo Fisher Scientific, Inc.). TGF- $\beta 1$ (PeproTech, Inc., Rocky Hill, NJ, USA) was used to induce EMT in MHCC97H cells. MHCC97H cells were treated with TGF- $\beta 1$ $(5,10,20$ and $40 \mathrm{ng} / \mathrm{ml})$ for $48 \mathrm{~h}$ at $37^{\circ} \mathrm{C}$. It was established that $10 \mathrm{ng} / \mathrm{ml} \mathrm{TGF}-\beta 1$ was sufficient to induce EMT in $\mathrm{MHCC} 97 \mathrm{H}$ cells. MHCC97H cells treated with $10 \mathrm{ng} / \mathrm{ml}$ TGF- $\beta 1$ for $48 \mathrm{~h}$ were labeled as the TGF- $\beta 1$ group. MHCC $97 \mathrm{HSYY}$ cells treated with $10 \mathrm{ng} / \mathrm{ml} \mathrm{TGF}-\beta 1$ and $2 \mathrm{mg} / \mathrm{ml} \mathrm{SYY} \mathrm{for} 48 \mathrm{~h}$ were labeled as the SYY+TGF- $\beta 1$ group. The MHCC97HSYY cells treated with $2 \mathrm{mg} / \mathrm{ml} \mathrm{SYY} \mathrm{were} \mathrm{labeled} \mathrm{as} \mathrm{the} \mathrm{SYY} \mathrm{group.}$ MHCC97H cells cultured for 4 weeks without SYY were used as a negative control.
Enzyme-linked immunosorbent assay (ELISA). MHCC97HSYY and MHCC97H cells were transferred into T-75 flasks at a density of $1 \times 10^{6}$ cells/flask and cultured overnight. The culture medium was subsequently replaced with $12 \mathrm{ml}$ serum-free DMEM and cells were incubated for a further $24 \mathrm{~h}$. The flasks were centrifuged at $800 \mathrm{x} g$ for $5 \mathrm{~min}$ at $4^{\circ} \mathrm{C}$ and the cell-free media were collected and stored at $-80^{\circ} \mathrm{C}$ until required. The concentration of TGF- $\beta 1$ secreted into the media was quantified using a human TGF- $\beta 1$ ELISA kit (cat. no. DB100B; R\&D Systems, Inc., Minneapolis, MN, USA), according to the protocol of the manufacturer. Optical density was measured using a microplate reader (Biotek Instruments, Inc., Winooski, VT, USA) at a wavelength of $450 \mathrm{~nm}$. A standard curve was generated by TGF- $\beta 1$ standard $(13.72,41.15$, $123.5,370.4,1,111,3,333$ and $10,000 \mathrm{pg} / \mathrm{ml}$ ) of the ELISA kits.

Cell invasion and migration assays. Transwell ${ }^{\circledR}$ plates (Corning Incorporated, Corning, NY, USA) were used to evaluate the invasion and migration of MHCC97H cells. The invasion assay was performed in 24-well Transwell culture plates coated with $25 \mu 1 \mathrm{BD}$ Matrigel $^{\mathrm{TM}}$ (BD Biosciences, Franklin Lakes, NJ, USA). A total of $5 \times 10^{4}$ MHCC $97 \mathrm{H}$ cells in serum-free DMEM were seeded into the upper chamber and $0.5 \mathrm{ml}$ DMEM containing $20 \%$ FBS was added to the lower chamber, with or without $10 \mathrm{ng} / \mathrm{ml}$ TGF- $\beta 1$. In total, $5 \times 10^{4} \mathrm{MHCC} 97 \mathrm{HSYY}$ cells in serum-free DMEM containing $2 \mathrm{mg} / \mathrm{ml} \mathrm{SYY} \mathrm{were} \mathrm{seeded}$ into the upper chamber, and DMEM containing 20\% FBS and $10 \mathrm{ng} / \mathrm{ml}$ TGF- $\beta 1$ was added to the lower chamber. The plates were incubated for $48 \mathrm{~h}$, and cells in the lower chamber were subsequently fixed with $4 \%$ paraformaldehyde for $30 \mathrm{~min}$ at room temperature. The cells were then stained with Giemsa (Sigma-Aldrich; Merck Millipore, Darmstadt, Germany) for 15 min and counted at magnification, x200 with a fluorescence microscope (DMI300B; Leica Microsystems GmbH, Wetzlar, Germany). The migration assay was performed as described above without the BD Matrigel coating.

Western blot analysis. Following a 4-week incubation, 5x10 MHCC97H and 5x106 MHCC97HSYY cells were washed twice with $\mathrm{PBS}$ and lysed in radioimmunoprecipitation assay buffer, containing $150 \mathrm{mM} \mathrm{NaCl}, 1 \%$ Triton $^{\mathrm{TM}}$ X-100 (Beyotime Institute of Biotechnology, Shanghai, China), $0.1 \%$ SDS, $50 \mathrm{mM}$ Tris- $\mathrm{HCl}$ (pH 7.4), 1 mM ethylenediaminetetraacetic acid and $1 \mathrm{mM}$ phenylmethylsulfonyl fluoride. The supernatants were collected following centrifugation at $10,000 \times \mathrm{g}$ for $15 \mathrm{~min}$ at $4^{\circ} \mathrm{C}$. Total protein concentration was determined using a BCA Protein Assay kit. Equal amounts of protein $(50 \mu \mathrm{g})$ were incubated at $100^{\circ} \mathrm{C}$ for $10 \mathrm{~min}$ and separated using SDS-PAGE on a $10 \%$ gel. The proteins were subsequently transferred to polyvinylidene fluoride membranes. Following blocking in $10 \%$ milk for $2 \mathrm{~h}$ at room temperature, the membranes were incubated with the primary antibodies at $4^{\circ} \mathrm{C}$ overnight. The membranes were subsequently washed three times with TBS/Tween $(0.05 \%$ Tween-20 in TBS) and incubated with the horseradish peroxidase-conjugated secondary antibody (cat. no. 7074; dilution, 1:5,000; Cell Signaling Technology, Inc., Danvers, MA, USA) at room temperature for $1 \mathrm{~h}$. Protein bands were visualized using the enhanced chemiluminescent substrate with SuperSignal West Pico Chemiluminescent Substrate kit (Pierce; Thermo 
A

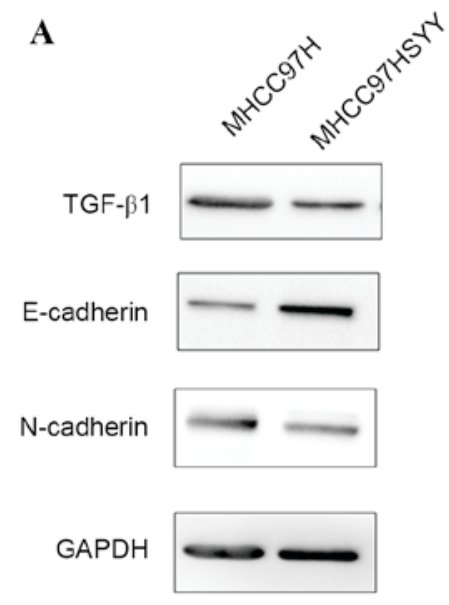

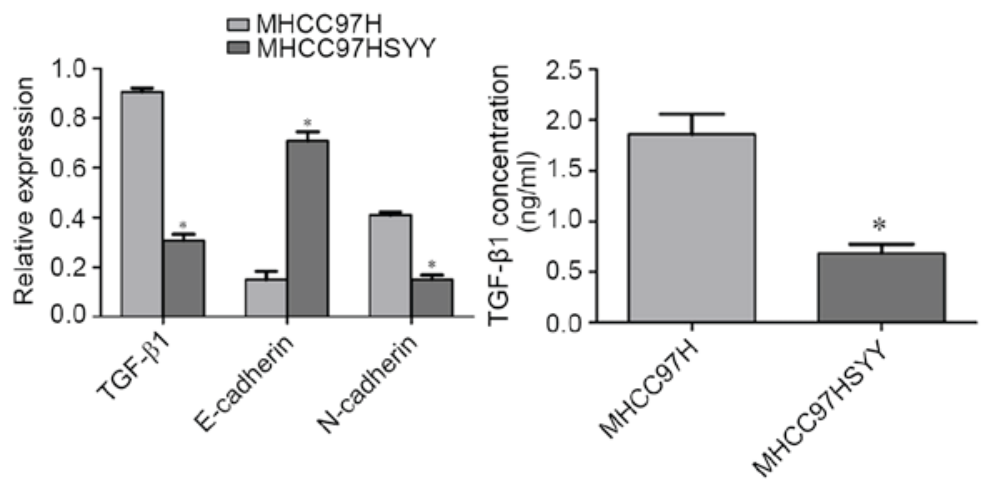

Figure 1. Effect of treatment with SYY on TGF- $\beta 1$, E-cadherin and N-cadherin protein expression. (A) Western blotting analysis of TGF- $\beta 1$, E-cadherin and N-cadherin expression demonstrated altered protein expression following treatment with SYY. Protein bands were normalized to GAPDH. (B) Results of the enzyme-linked immunosorbent assay demonstrated decreased TGF- $\beta 1$ secretion following treatment with SYY. ${ }^{*}<0.05$ vs. untreated MHCC97H cells. SYY, Songyou Yin; TGF- $\beta 1$, transforming growth factor- $\beta 1$.

Fisher Scientific, Inc.). Positive immunoreactive bands were quantified using densitometry and normalized to GAPDH (Image lab software, version 4.1; Bio-Rad Laboratories, Inc., Hercules, CA, USA). Primary antibodies were used as follows: Anti-E-cadherin (cat no. 3195; dilution, 1:1,000; Cell Signaling Technology, Inc.), anti-N-Cadherin (cat no. 13116; dilution, 1:1,000; Cell Signaling Technology, Inc.), anti-phosphorylated (p)-SMAD2 (cat. no. 3108; dilution, 1:1,000; Cell Signaling Technology, Inc.), anti-p-SMAD3 (cat. no. 9520; dilution, 1:1,000; Cell Signaling Technology, Inc.), anti-SMAD2 (cat. no. 5339; dilution, 1:1,000; Cell Signaling Technology, Inc.), anti-SMAD3 (cat. no. 9523; dilution, 1:1,000; Cell Signaling Technology, Inc.), anti-TGF- $\beta 1$ (cat. no. ab92486; dilution, 1:1,000; Abcam) and anti-GAPDH (cat no. 5174; dilution, 1:5,000; Cell Signaling Technology, Inc.).

Immunofluorescent staining. E-cadherin expression in the TGF- $\beta 1$, SYY+TGF- $\beta 1$ and SYY groups was evaluated using immunofluorescent staining. Following $48 \mathrm{~h}$ of treatment with or without TGF- $\beta 1,5 \times 10^{4}$ cells were fixed with $4 \%$ paraformaldehyde in PBS at room temperature for $10 \mathrm{~min}$. Nonspecific binding sites were blocked using $1 \%$ bovine serum albumin (BSA; Sigma-Aldrich; Merck Millipore) at room temperature for $30 \mathrm{~min}$. A rabbit polyclonal antibody against E-cadherin (as aforementioned) was diluted in PBS containing 1\% BSA (1:50) and incubated with the fixed cells at $40^{\circ} \mathrm{C}$ overnight. Cells were subsequently washed three times with $1 \%$ BSA prior to incubation with a fluorescein isothiocyanate-labeled goat anti-rabbit immunoglobulin G antibody (cat. no. 35562; dilution, 1:200; Thermo Fisher Scientific, Inc.) at room temperature for $30 \mathrm{~min}$. The fixed cells were washed three times and subsequently stained with DAPI for $10 \mathrm{~min}$, prior to the capturing of images. The images were captured at magnification, x200 using an inverted microscope (DMI300B; Leica Microsystems $\mathrm{GmbH}$ ), whereby the anti-E-cadherin antibody was excited by green light and DAPI by ultraviolet light. In addition, changes in cell morphology were assessed with microscopy (DMI300B; Leica Microsystems GmbH). The
MHCC97H cells were treated with 0, 5, 10, 20 and $40 \mathrm{ng} / \mathrm{ml}$ TGF- $\beta 1$ for $48 \mathrm{~h}$ and images were captured at magnification, $\mathrm{x} 100$ to evaluate the changes of the cell shapes. The typical feature of the mesenchymal phenotype were observed, which exhibited as scattered, lengthened and a spindle-like shape.

Statistics analysis. Statistical analysis was performed using the Student's t-test and SPSS 17.0 software (SPSS, Inc., Chicago, IL, USA). $\mathrm{P}<0.05$ was considered to indicate a statistically significant difference. All experiments were repeated three times, and the values are presented as the mean \pm standard deviation of triplicate experiments.

\section{Results}

Effect of treatment with SYY on EMT marker and TGF- $\beta 1$ expression in $\mathrm{MHCC} 97 \mathrm{H}$ cells. To determine the effect of treatment with SYY on EMT, E-cadherin and N-cadherin protein expression was evaluated using western blotting. The results demonstrated that treatment with SYY significantly decreased $\mathrm{N}$-cadherin expression and increased E-cadherin expression compared with the untreated MHCC97H cells $(\mathrm{P}=0.011$ and $\mathrm{P}=0.002$, respectively; Fig. 1A). In addition, the effect of treatment with SYY on TGF- $\beta 1$ expression in MHCC97HSYY and $\mathrm{MHCC} 97 \mathrm{H}$ cells was investigated using western blotting. Significantly decreased TGF- $\beta 1$ protein expression was observed in the MHCC97HSYY cells compared with the MHCC97H cells $(\mathrm{P}=0.004$; Fig. 1A). To further determine whether treatment with SYY regulated TGF- $\beta 1$ secretion in HCC cells, the concentration of TGF- $\beta 1$ secreted into the culture media was evaluated using an ELISA. MHCC97HSYY cells exhibited significantly decreased levels of secreted TGF- $\beta 1$ compared with MHCC97H cells ( $\mathrm{P}=0.03$; Fig. 1B). These results demonstrate that treatment with SYY alters EMT marker expression and inhibits TGF- $\beta 1$ expression in MHCC97H cells.

TGF- $\beta 1$ induces EMT in MHCC97H cells. The optimum TGF- $\beta 1$ concentration required to initiate EMT in $\mathrm{MHCC} 97 \mathrm{H}$ 
A
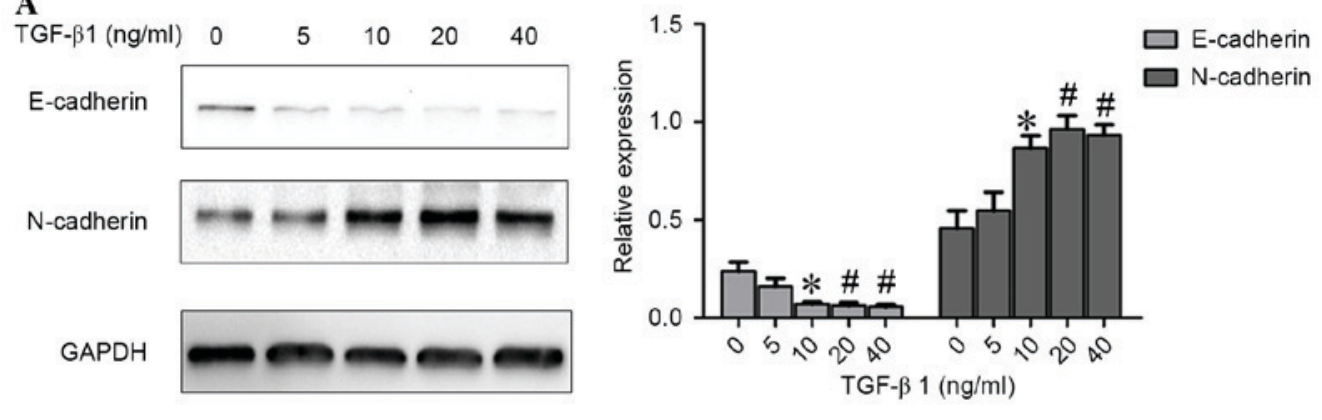

B
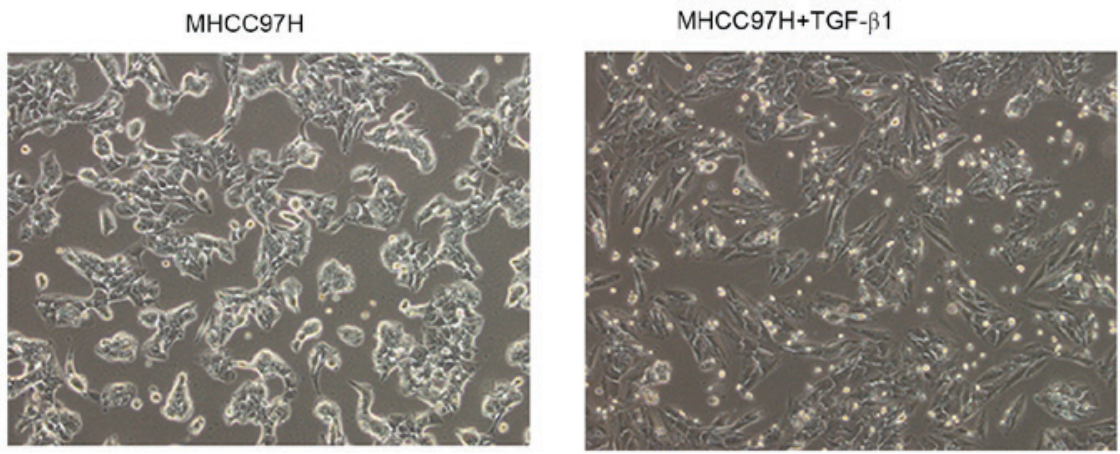

Figure 2. TGF- $\beta 1$ induces epithelial-mesenchymal transition in MHCC97H cells. (A) MHCC97H cells were treated with 0, 5, 10, 20 and 40 ng/ml TGF- $\beta 1$, and western blot analysis demonstrated altered E-cadherin and $\mathrm{N}$-cadherin protein expression. Protein bands were normalized to GAPDH. "P<0.05 vs. untreated MHCC $97 \mathrm{H}$ cells; ${ }^{*} \mathrm{P}<0.05$ vs. MHCC97H cells treated with $10 \mathrm{ng} / \mathrm{ml}$ TGF- $\beta 1$. (B) Representative images of morphological changes in MHCC97H cells treated with or without $10 \mathrm{ng} / \mathrm{ml}$ TGF- $\beta 1$. Images are shown at magnification, x100. TGF- $\beta 1$, transforming growth factor- $\beta 1$.

cells was initially determined. Changes in cell morphology were assessed following treatment with $0,5,10,20$ and $40 \mathrm{ng} / \mathrm{ml}$ TGF- $\beta 1$ for $48 \mathrm{~h}$. E-cadherin and N-cadherin expression was determined following treatment of MHCC97H cells with TGF- $\beta 1$. Western blotting demonstrated a dose-dependent decrease in E-cadherin protein expression and a significant decrease following treatment with $10 \mathrm{ng} / \mathrm{ml}$ TGF- $\beta 1(\mathrm{P}=0.008$; Fig. 2A). By contrast, $\mathrm{N}$-cadherin expression was increased in a dose-dependent manner and was significantly increased following treatment with $10 \mathrm{ng} / \mathrm{ml}$ TGF- $\beta 1$ ( $\mathrm{P}=0.017$; Fig. 2A). In addition, $\mathrm{E}-$ and $\mathrm{N}$-cadherin expression levels were not significantly altered in MHCC $97 \mathrm{H}$ cells following treatment with 20 and $40 \mathrm{ng} / \mathrm{ml}$ TGF- $\beta 1$ compared with cells treated with $10 \mathrm{ng} / \mathrm{ml}$ TGF- $\beta 1$ (for E-cadherin, $\mathrm{P}=0.497$ and 0.369 respectively; for $\mathrm{N}$-cadherin, $\mathrm{P}=0.1$ and 0.116 respectively; Fig. $2 \mathrm{~A}$ ). Following treatment with $10 \mathrm{ng} / \mathrm{ml}$ TGF- $\beta 1$, MHCC $97 \mathrm{H}$ cells also underwent morphological changes, and gained an elongated and spindle-like morphology (Fig. 2B). These results indicate that TGF- $\beta 1$ initiates EMT in MHCC97H cells.

Treatment with SYY suppresses TGF- $\beta 1$-induced EMT in MHCC $97 H$ cells. The effect of treatment with SYY on TGF- $\beta 1$-induced EMT was investigated. Cells in the SYY group exhibited classical epithelial morphology, while cells in the TGF- $\beta 1$ group exhibited a mesenchymal morphology. However, cells treated with SYY and TGF- $\beta 1$ seemed to change little, and still exhibited epithelial morphology without exhibiting an elongated and fibroblast-like phenotype (Fig. 3A). Western blotting was also used to evaluate changes in protein expression levels of the EMT markers E- and N-cadherin. As presented in Fig. 3B, E-cadherin expression was significantly decreased $(\mathrm{P}=0.016)$ and $\mathrm{N}$-cadherin expression was significantly increased $(\mathrm{P}=0.014)$ in the TGF- $\beta 1$ group compared with the SYY+TGF- $\beta 1$ group. To determine the distribution of E-cadherin in HCC cells, immunofluorescent staining was performed. As presented in Fig. 3C, membrane E-cadherin expression was lost in MHCC97H cells treated with TGF- $\beta 1$, whereas membrane E-cadherin expression was partially restored in the SYY+TGF- $\beta 1$ group. Furthermore, the effects of treatment with SYY on TGF- $\beta 1$-induced invasion and migration in $\mathrm{MHCC} 97 \mathrm{H}$ cells were investigated. As presented in Fig. 3D, no significant difference in the numbers of migratory and invasive cells was observed between the SYY and SYY+TGF- $\beta 1$ groups. However, the number of invasive and migratory cells in the SYY+TGF- $\beta 1$ group was significantly decreased compared with the TGF- $\beta 1$ group $(\mathrm{P}=0.021$ and 0.002 , respectively). These results demonstrate that treatment with TGF- $\beta 1$ is able to promote HCC cell invasion and migration, and that pretreatment with SYY inhibits these effects, indicating that SYY inhibits TGF- $\beta 1$-induced EMT.

Treatment with SYY inhibits SMAD2 and 3 phosphorylation. Phosphorylation of SMAD2 and 3 by the activated type I TGF- $\beta$ receptor is a critical step in the initiation of TGF- $\beta 1$ signal transduction. Therefore, the effect of pretreatment with SYY on SMAD expression was investigated. Cells in the SYY, TGF- $\beta 1$ and SYY+TGF- $\beta 1$ groups were compared. As presented in Fig. 4, no significant difference in total SMAD2 and 3 protein expression was observed between cell groups. However, p-SMAD2 and 3 expression was significantly increased in cells in the TGF- $\beta 1$ group compared with cells in the SYY+TGF- $\beta 1$ group ( $\mathrm{P}=0.014$ and 0.002 , respectively). No significant difference in p-SMAD2 and 3 expression was observed between the SYY+TGF- $\beta 1$ and SYY groups. These 
A
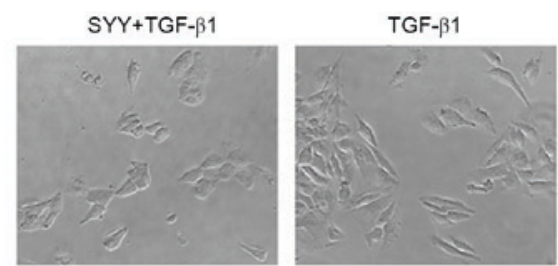

B

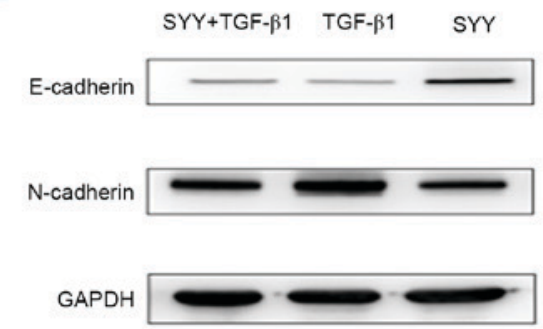

C
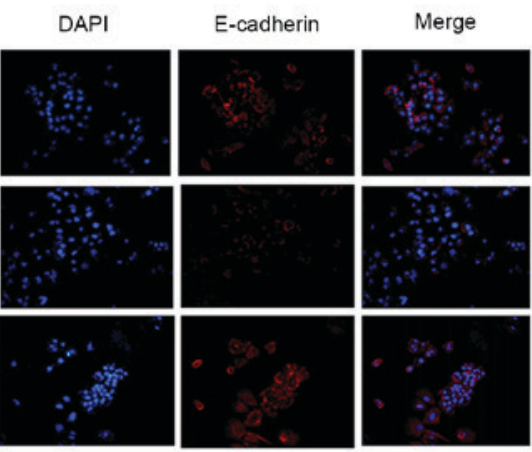

D

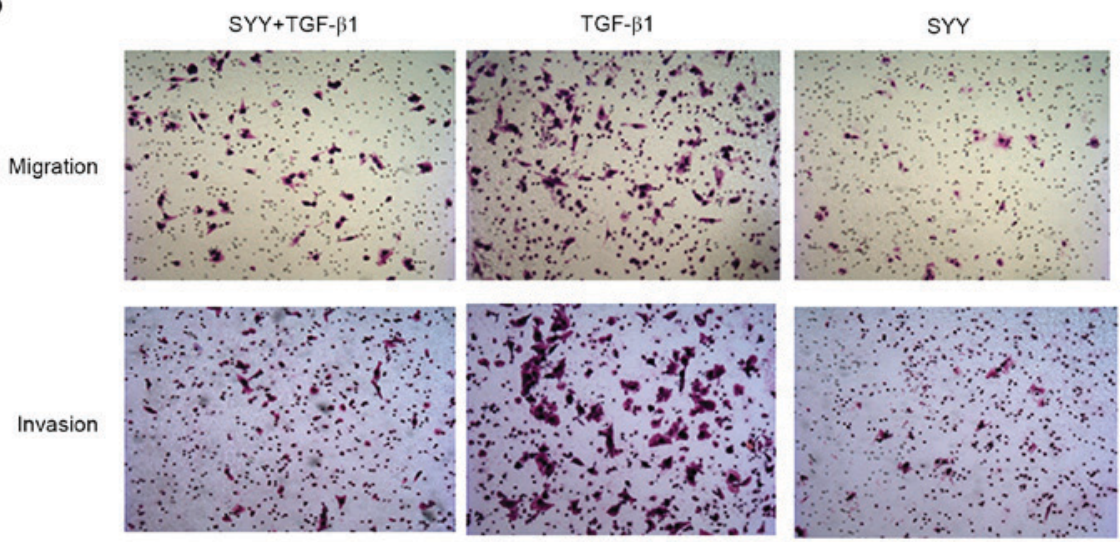

Migration

Invasion
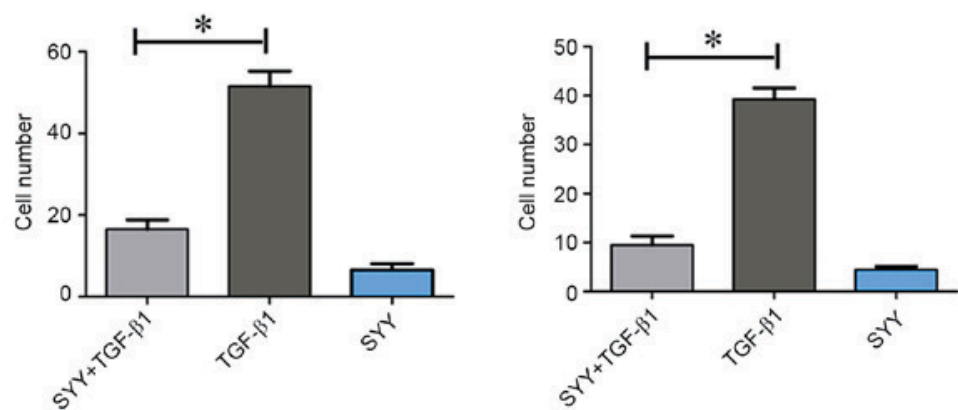

Figure 3. Treatment with SYY suppresses TGF- $\beta 1$-induced epithelial-mesenchymal transition in MHCC97H cells. (A) Representative images of MHCC97H cell morphological changes in the SYY+TGF- $\beta 1$, TGF- $\beta 1$ and SYY groups. Magnification, x200. (B) Western blot analysis of E- and N-cadherin protein expression following treatment with SYY and TGF- $\beta 1$. Protein bands were normalized to GAPDH. (C) Representative images of the immunofluorescent staining of membrane E-cadherin in the three groups. Magnification, x20. (D) Results from the invasion and migration assays demonstrating the increased invasive and migratory capacity of cells in the TGF- $\beta 1$ group. Magnification, $x 200$. "P $<0.05$. SYY, Songyou Yin; TGF- $\beta 1$, transforming growth factor- $\beta 1$. 


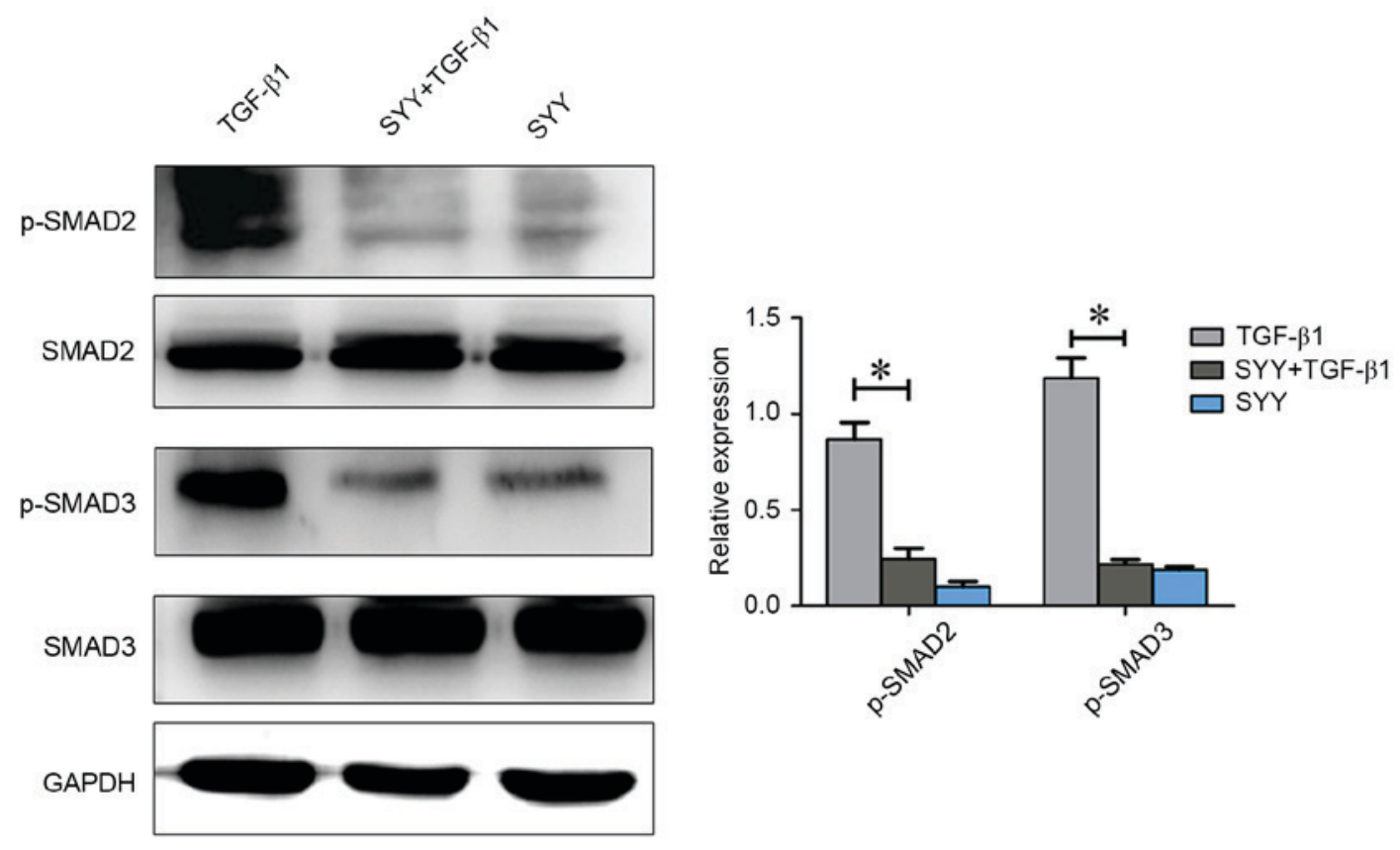

Figure 4. Western blot analysis of SMAD2 and 3, and p-SMAD2 and 3 expression in the three groups. Protein bands were normalized to GAPDH. "P<0.05. SMAD, mothers against decapentaplegic homolog; , phosphorylated.

results suggest that treatment with SYY decreases SMAD2 and 3 phosphorylation.

\section{Discussion}

Metastasis is the primary obstacle in the management of patients with HCC. EMT significantly contributes to the conversion of early stage tumors into invasive malignancies. EMT is triggered by various external signals, including TGF- $\beta 1$, hepatocyte growth factor and fibroblast growth factor (26). Furthermore, TGF- $\beta 1$ is involved in the EMT of HCC metastases (13). In the present study, it was observed that TGF- $\beta 1$ induced EMT in MHCC97H cells, suggesting that MHCC97H cells are sensitive to inducers of EMT. Treatment with TGF- $\beta 1$ caused MHCC $97 \mathrm{H}$ cells to lose their polygonal appearance, and altered the expression of cell adhesion molecules, including E- and $\mathrm{N}$-cadherin, which are characteristics of EMT. Furthermore, TGF- $\beta 1$ was demonstrated to be able to induce EMT in HCC cells in a dose-dependent manner. A total of $10 \mathrm{ng} / \mathrm{ml}$ TGF- $\beta 1$ was used in to induce EMT in the subsequent in vitro experiments. In addition, the results of the present study demonstrated that TGF- $\beta 1$ was a strong inducer of tumor cell metastasis.

SYY is a Chinese herbal formula and certain components have been recognized to be effective in the treatment of cancer $(27,28)$. Astragaloside IV controls collagen reduction in photoaging skin by improving suppression of the TGF- $\beta /$ SMAD signaling pathway (29). Combined treatment with A. membranaceus and S. miltiorrhiza extracts significantly suppressed HCC progression, by mediating TGF- $\beta / S M A D$ signaling and modulating SMAD3 phosphorylation (30). In a previous study, it was reported that treatment with SYY inhibited the molecular changes characteristic of EMT in oxaliplatin-treated tumor tissues and cell lines (24). In the present study, it was investigated whether SYY inhibited TGF- $\beta 1$-induced EMT in HCC cells. Treatment with SYY was demonstrated to inhibit TGF- $\beta 1$ expression and secretion in MHCC97H cells. Treatment with SYY was also able to inhibit TGF- $\beta 1$-induced morphological changes in HCC cells. Western blot analysis demonstrated that treatment with SYY significantly increased E-cadherin protein expression and significantly decreased $\mathrm{N}$-cadherin expression. Furthermore, the number of invasive and migratory cells in the SYY+TGF- $\beta 1$ group was significantly decreased compared with the TGF- $\beta 1$ group, suggesting that SYY effectively inhibits TGF- $\beta 1$-induced MHCC $97 \mathrm{H}$ cell invasion and migration. The results of the present study demonstrate that TGF- $\beta 1$ induces EMT in MHCC97H cells and that this process is effectively inhibited by pretreatment with SYY.

TGF- $\beta 1$ signaling begins with the binding of TGF- $\beta$ receptors, and phosphorylation of SMAD2 and 3, thereby activating multiple downstream signaling pathways $(31,32)$. As treatment with SYY was demonstrated to inhibit TGF- $\beta 1$ expression and TGF- $\beta 1$-induced morphological changes, the effect of treatment with SYY on TGF- $\beta 1$ signaling elements was subsequently investigated. In the present study, it was observed that TGF- $\beta 1$ induced upregulation of p-SMAD2 and 3 expression, and that these changes were significantly inhibited by pretreatment with SYY. SYY appears to inhibit EMT via downregulation of TGF- $\beta 1$-induced $\mathrm{p}$-SMAD2 and 3 expression, which is consistent with previous studies $(33,34)$.

In conclusion, it was demonstrated that treatment with SYY inhibits TGF- $\beta 1$-induced EMT through attenuation of TGF- $\beta 1$ expression, and downregulation of SMAD2 and 3 phosphorylation. These results further support the therapeutic potential of SYY in the treatment of HCC and inhibition of EMT. Therefore, future research into the clinical efficacy of SYY treatment in patients with HCC is warranted. 


\section{Acknowledgements}

The present study was supported by the National Natural Science Foundation of China (grant no. 81173391).

\section{References}

1. Jemal A, Bray F, Center MM, Ferlay J, Ward E and Forman D Global cancer statistics. CA Cancer J Clin 61: 69-90, 2011.

2. Shim JH, Jun MJ, Han S, Lee YJ, Lee SG, Kim KM, Lim YS and Lee HC: Prognostic nomograms for prediction of recurrence and survival after curative liver resection for hepatocellular carcinoma. Ann Surg 261: 939-946, 2015.

3. Tang ZY, Ye SL, Liu YK, Qin LX, Sun HC, Ye QH, Wang L, Zhou J, Qiu SJ, Li Y et al: A decade's studies on metastasis of hepatocellular carcinoma. J Cancer Res Clin Oncol 130: 187-196, 2004.

4. Garber K: Epithelial-to-mesenchymal transition is important to metastasis, but questions remain. J Natl Cancer Inst 100: 232-233, 239, 2008.

5. Tsuji T, Ibaragi S and Hu GF: Epithelial-mesenchymal transition and cell cooperativity in metastasis. Cancer Res 69: 7135-7139, 2009.

6. Thiery JP, Acloque H, Huang RY and Nieto MA: Epithelial-mesenchymal transitions in development and disease. Cell 139: 871-890, 2009.

7. Nieto MA: Epithelial plasticity: A common theme in embryonic and cancer cells. Science 342: 1234850, 2013.

8. Micalizzi DS and Ford HL: Epithelial-mesenchymal transition in development and cancer. Future Oncol 5: 1129-1143, 2009.

9. van Zijl F, Zulehner G, Petz M, Schneller D, Kornauth C, Hau M, Machat G, Grubinger M, Huber H and Mikulits W: Epithelial-mesenchymal transition in hepatocellular carcinoma. Future Oncol 5: 1169-1179, 2009.

10. Ogunwobi OO and Liu C: Therapeutic and prognostic importance of epithelial-mesenchymal transition in liver cancers: Insights from experimental models. Crit Rev Oncol Hematol 83: 319-328, 2012

11. Fang JH, Zhou HC, Zhang C, Shang LR, Zhang L, Xu J, Zheng L, Yuan Y, Guo RP, Jia WH et al: A novel vascular pattern promotes metastasis of hepatocellular carcinoma in an epithelial-mesenchymal transition-independent manner. Hepatology 62: 452-465, 2015.

12. Zavadil J and Bottinger EP: TGF-beta and epithelial-to-mesenchymal transitions. Oncogene 24: 5764-5774, 2005.

13. Reichl P, Haider C, Grubinger M and Mikulits W: TGF- $\beta$ in epithelial to mesenchymal transition and metastasis of liver carcinoma. Curr Pharm Des 18: 4135-3147, 2012.

14. Steinway SN, Zañudo JG, Ding W, Rountree CB, Feith DJ, Loughran TP Jr and Albert R: Network modeling of TGF $\beta$ signaling in hepatocellular carcinoma epithelial-to-mesenchyma transition reveals joint sonic hedgehog and Wnt pathway activation. Cancer Res 74: 5963-5977, 2014.

15. Massague J: How cells read TGF-beta signals. Nat Rev Mol Cell Biol 1: 169-178, 2000

16. Saitoh M: Epithelial-mesenchymal transition is regulated at post-transcriptional levels by transforming growth factor- $\beta$ signaling during tumor progression. Cancer Sci 106: 481-488, 2015.

17. Shi Y and Massagué J: Mechanisms of TGF-beta signaling from cell membrane to the nucleus. Cell 113: 685-700, 2003.

18. Li L, Wei L, Shen A, Chu J, Lin J and Peng J: Oleanolic acid modulates multiple intracellular targets to inhibit colorectal cancer growth. Int J Oncol 47: 2247-2254, 2015.
19. Naksuriya O, Okonogi S, Schiffelers RM and Hennink WE: Curcumin nanoformulations: A review of pharmaceutical properties and preclinical studies and clinical data related to cancer treatment. Biomaterials 35: 3365-3383, 2014.

20. Liu Y, Cao W, Zhang B, Liu YQ, Wang ZY, Wu YP, Yu XJ, Zhang XD, Ming PH, Zhou GB and Huang L: The natural compound magnolol inhibits invasion and exhibits potential in human breast cancer therapy. Sci Rep 3: 3098, 2013.

21. Huang XY, Wang L, Huang ZL, Zheng Q, Li QS and Tang ZY: Herbal extract 'Songyou Yin' inhibits tumor growth and prolongs survival in nude mice bearing human hepatocellular carcinoma xenograft with high metastatic potential. J Cancer Res Clin Oncol 135: 1245-1255, 2009.

22. Jia QA, Wang ZM, Ren ZG, Bu Y, Xie XY, Wang YH, Zhang L, Zhang QB, Xue TC, Deng LF and Tang ZY: Herbal compound 'Songyou Yin' attenuates hepatoma cell invasiveness and metastasis through downregulation of cytokines secreted by activated hepatic stellate cells. BMC Complement Altern Med 13: 89, 2013.

23. Bu Y, Jia QA, Ren ZG, Xue TC, Zhang QB, Zhang KZ, Zhang QB, You Y, Tian H, Qin LX and Tang ZY: The herbal compound Songyou Yin (SYY) inhibits hepatocellular carcinoma growth and improves survival in models of chronic fibrosis via paracrine inhibition of activated hepatic stellate cells. Oncotarget 6: 40068-40080, 2015.

24. Xiong W, Ren ZG, Qiu SJ, Sun HC, Wang L, Liu BB, Li QS, Zhang W, Zhu XD, Liu L et al: Residual hepatocellular carcinoma after oxaliplatin treatment has increased metastatic potential in a nude mouse model and is attenuated by Songyou Yin. Bmc Cancer 10: 219, 2010.

25. Tian J, Tang ZY, Ye SL, Liu YK, Lin ZY, Chen J and Xue Q: New human hepatocellular carcinoma (HCC) cell line with highly metastatic potential (MHCC97) and its expressions of the factors associated with metastasis. Br J Cancer 81: 814-821, 1999.

26. Lee JM, Dedhar S, Kalluri R and Thompson EW: The epithelial-mesenchymal transition: New insights in signaling, development, and disease. J Cell Biol 172: 973-981, 2006.

27. Luo Y, Xu DQ, Dong HY, Zhang B, Liu Y, Niu W, Dong MQ and Li ZC: Tanshinone IIA inhibits hypoxia-induced pulmonary artery smooth muscle cell proliferation via Akt/Skp2/p27-associated pathway. PLoS One 8: e56774, 2013.

28. Zhu J, Zhang H, Zhu Z, Zhang Q, Ma X, Cui Z and Yao T: Effects and mechanism of flavonoids from Astragalus complanatus on breast cancer growth. Naunyn Schmiedebergs Arch Pharmacol 388: 965-972, 2015.

29. Chen B, Li R, Yan N, Chen G, Qian W, Jiang HL, Ji C and Bi ZG: Astragaloside IV controls collagen reduction in photoaging skin by improving transforming growth factor- $\beta /$ Smad signaling suppression and inhibiting matrix metalloproteinase-1. Mol Med Rep 11: 3344-3348, 2015

30. Hu X, Rui W, Wu C, He S, Jiang J,Zhang X and Yang Y: Compound Astragalus and Salvia miltiorrhiza extracts suppress hepatocarcinogenesis by modulating transforming growth factor- $\beta / \mathrm{Smad}$ signaling. J Gastroenterol Hepatol 29: 1284-1291, 2014.

31. Massague J: TGF $\beta$ signalling in context. Nat Rev Mol Cell Biol 13: 616-630, 2012.

32. Akhurst RJ and Hata A: Targeting the TGF $\beta$ signalling pathway in disease. Nat Rev Drug Discov 11: 790-811, 2012.

33. Bokhari AA, Lee LR, Raboteau D, Hamilton CA, Maxwell GL, Rodriguez GC and Syed V: Progesterone inhibits endometrial cancer invasiveness by inhibiting the TGF $\beta$ pathway. Cancer Prev Res (Phila) 7: 1045-1055, 2014.

34. Liu LC, Tsao TC, Hsu SR, Wang HC, Tsai TC, Kao JY and Way TD: EGCG inhibits transforming growth factor- $\beta$-mediated epithelial-to-mesenchymal transition via the inhibition of Smad2 and Erk1/2 signaling pathways in nonsmall cell lung cancer cells. J Agric Food Chem 60: 9863-9873, 2012. 